\title{
Microstructure of PZT sol-gel films on Pt-substrates with different adhesion layers
}

\author{
R. D. Klissurska, Keith G. Brooks, Thomas Maeder and Nava Setter \\ Laboratoire de Céramique, Ecole Polytechnique Fédérale de Lausanne, CH-1015 Lausanne, Switzerland. \\ Version of record: Microelectronic Engineering 29 (1-4), 297-300, 1995. \\ http://hdl.handle.net/10.1016/0167-9317(95)00164-6
}

\begin{abstract}
The effects of $\mathrm{Ta}, \mathrm{Ti}$ and $\mathrm{TiO}_{2}$ adhesion layers with $\mathrm{Pt}$ bottom electrodes and the metallization deposition temperature on the nucleation and growth of sol-gel derived $\mathrm{Pb}\left(\mathrm{Zr}_{0.53} \mathrm{Ti}_{0.47}\right) \mathrm{O}_{3}$ thin films is reported. Several different PZT annealing profiles were simultaneously investigated to determine the role of metallization and PZT annealing on resultant PZT film microstructures. The adhesion layer was found to strongly influence the PZT grain size and occurrence of residual pyrochlore on the film surfaces. These results were correlated to the stability of the adhesion layers in terms of diffusion through $\mathrm{Pt}$ and thus changes in the chemistry and structure of the film/Pt interface where the perovskite nucleation was observed to occur. Slower heating rates were resulted rosette type structures and a large volume of residual pyrochlore, particularly in films deposited on $\mathrm{TiO}_{2}$ substrates. Correlations are made between the adhesion layer deposition temperature, degree of Pt orientation and resulting PZT texture. Different heating rates for the perovskite crystallization were studied and showed that the degree of perovskite texture and the preferred orientation could be influenced for the $\mathrm{TiO}_{2}$ bonded substrates, but had little or no effect for the $\mathrm{Ta}$ and $\mathrm{Ti}$ bonded substrates. Ferroelectric properties of the various films are also discussed in view of the microstructural observations. The development of rosette structures and increased volume of second phase on $\mathrm{TiO}_{2}$ bonded substrates, indicated a low concentration of nucleation sites. This result is in agreement with RBS-evidence from previous investigations.
\end{abstract}

\section{Introduction}

$\mathrm{Pb}\left(\mathrm{Zr}_{x} \mathrm{Ti}_{1-x}\right) \mathrm{O}_{3}(\mathrm{PZT})$ thin films on silicon substrates are investigated for different device applications, due to their ferroelectric, piezoelectric and pyroelectric properties. The film microstructural features and electrical properties required are dictated by the intended application. Properties are optimized by selecting the proper composition and controlling the film microstructure.

For a given PZT composition, different microstructural features (e.g. texture, grain size) are dependent upon the substrate structure and the PZT annealing profile through the perovskite nucleation and crystallization mechanisms [1]. Nucleation is controlled by the bottom electrode/film interface, and nuclei growth by the stability of the transient pyrochlore phase [2,3]. Grain size is also influenced by the nucleation process. In this study, different Pt adhesion layers and PZT annealing profiles were investigated. The quantity of residual pyrochlore observed of a given annealing profile and substrate is an indication of the efficiency of perovskite nucleation. Determination of the substrate parameters which influence the preferred perovskite orientation was also studied.

\section{Experimental}

Ti-Pt, $\mathrm{TiO}_{2}-\mathrm{Pt}$ and Ta-Pt metallizations were sputter deposited onto $\mathrm{Si}_{-} \mathrm{SiO}_{2}$ substrates. The thickness of the adhesion layer $\left(\mathrm{Ti}, \mathrm{TiO}_{2}, \mathrm{Ta}\right)$ and $\mathrm{Pt}$ were 10 and $100 \mathrm{~nm}$, respectively. All films were prepared by a previously described sol-gel technique [4]. Precursor solutions with $10 \%$ excess $\mathrm{Pb}$ were utilized. Films were prepared from a $0.4 \mathrm{M}$ solution by spin coating at $3000 \mathrm{rpm}$ using a multiple coating process with each layer pyrolyzed at $350^{\circ} \mathrm{C}$ for $15 \mathrm{~s}$. Films of $\approx 0.30 \mu \mathrm{m}$ thickness were prepared by the application of 5 layers. Four sets of films were prepared being crystallized by employment of five different annealing profiles at $650^{\circ} \mathrm{C}$, as given in Table 1 . Films were characterized by XRD, SEM (JEOL 6300, Japan), and TEM (EM 430, Philips, Holland). 
Table 1. PZT annealing profiles investigated

\begin{tabular}{ll}
\hline$\#$ & Profile \\
\cline { 1 - 1 } 1 & 20s to $525^{\circ} \mathrm{C}$, hold $1 \mathrm{~min}, 4 \mathrm{~s}$ to $650^{\circ} \mathrm{C}$, hold $30 \mathrm{~min}$, cool to $25^{\circ} \mathrm{C}$ \\
2 & $10 \mathrm{~s}$ to $650^{\circ} \mathrm{C}$, hold $30 \mathrm{~min}$, cool \\
3 & $30 \mathrm{~s}$ to $650^{\circ} \mathrm{C}$, hold $30 \mathrm{~min}$, cool \\
4 & $20 \mathrm{~s}$ to $450^{\circ} \mathrm{C}$, hold $10 \mathrm{~min}, 5 \mathrm{~s}$ to $650^{\circ} \mathrm{C}$, hold $30 \mathrm{~min}$, cool \\
5 & $10 \mathrm{~s}$ to $650^{\circ} \mathrm{C}$, hold $5 \mathrm{~min}$, cool \\
\hline
\end{tabular}

\section{Results}

Table 2 presents the preferred orientation as a function of adhesion layer, metallization deposition temperature, and PZT annealing profile. The substrate adhesion layer and its deposition temperature were found to influence the preferred orientation. For all substrate structures a preferred orientation of essentially (111) was obtained for all adhesion layers deposited at $500^{\circ} \mathrm{C}$. The set of films on the substrate with $\mathrm{TiO}_{2}$ adhesion layer which was deposited at $650^{\circ} \mathrm{C}$ are of (100) preferred orientation. Thus the adhesion layer deposition temperature strongly influenced the preferred orientation. As shown in Table 2, changing the PZT annealing profile can also affect the film texture. These results can be related to the orientation of the Pt metallization orientation on the different adhesion layers. All metallizations are essentially (111) oriented. However, the degree of misalignment of the (111) planes with the film varies strongly. From x-ray theta scans (remaining on the (111) reflection while varying substrate orientation), one can extract the fraction of $\mathrm{Pt}$ which is within a certain deviation (111) parallel to plane. The purely metallic (with metallic adhesion layer) $\mathrm{Pt}$ electrodes have much better alignment, probably due to the difficulty of nucleating the $\mathrm{Pt}$ on the $\mathrm{TiO}_{2}$.

This explains on the one hand the observed (111) texture of the PZT on the purely metallic substrates and also relates the better alignment to diffusion of the metallic layers through Pt profiles [5] (e.g. Ti or Ta oxides) to help nucleate the PZT. The heating profile was found to influence the PZT nucleation and growth kinetics and, for the $\mathrm{TiO}_{2}$ adhesion layers, to yield orientation reversal (Table 2). The change in orientation with annealing conditions for substrates with oxide adhesion layers agrees with the poorer orientations of $\mathrm{Pt}$ and the absence of defects (e.g. diffusion Fig.1 and Table 3).

The occurrence of residual surface pyrochlore was found to depend strongly on the substrate structure and annealing profile. For films deposited on substrates with $\mathrm{TiO}_{2}$ adhesion layer, the retained pyrochlore volume was found to be in general larger and much ore sensitive to the heating rate, employed for the crystallization of the PZT films, than for Ti and Ta ones, Table 2. Slower heating rates (profile 3) and step profiles ( 1 and 4) favored pyrochlore retention. The stronger influence of the slower heating rates and step anneals on pyrochlore volume for metallizations with oxide adhesion layers indicate, that the perovskite crystallization kinetics are dependent on the metallization. Although PZT annealing profiles will have influence on the diffusion kinetics of (Ti,Ta), which takes place during PZT annealing, PZT microstructure development was found to be primarily determined by the composition and deposition conditions of the metallizations. Pt hillocks were never observed. On $\mathrm{TiO}_{2}-\mathrm{Pt}$, due to absence of diffusion defects, perovskite crystallization kinetics are slower, allowing the pyrochlore phase to become more stable, and thus incomplete transformation to perovskite occurs when slower heating rates are chosen.

SEM micrographs, demonstrating the microstructure and grain size as a function of substrate structure and PZT annealing profiles are presented in Fig. 2. The largest grain size was obtained for $\mathrm{TiO}_{2}$ adhesion layer and this result held for all of the PZT annealing profiles studied. The increased pyrochlore content and development of rosette structures for films crystallized by using slower heating rates on substrates with $\mathrm{TiO}_{2}$ adhesion layers (Fig. 2a) are in agreement with a retardation of perovskite nucleation at the PZT/Pt 
interface. Much smaller grain sizes were observed for substrates with a Ti adhesion layer. In this case no rosette structures were observed for the slow heating rates. These results emphasize the strong differences in the PZT nucleation conditions for substrates with $\mathrm{TiO}_{2}$ and $\mathrm{Ti}$ adhesion layers. The better alignment of Pt observed on the purely metallic substrates ( $\mathrm{Ti}$ and $\mathrm{Ta}$ ) is also in agreement with easier nucleation on those substrates.

Table 2. Summary of XRD results for different substrates and PZT annealing profiles.

\begin{tabular}{|c|c|c|c|c|c|}
\hline \multirow[t]{2}{*}{ Substrate } & \multicolumn{5}{|c|}{ PZT Annealing Profile } \\
\hline & $\# 1$ & $\# 2$ & $\# \mathbf{3}$ & $\# \mathbf{4}$ & $\# \mathbf{5}$ \\
\hline $\begin{array}{c}\mathrm{TiO}_{2} \\
650^{\circ} \mathrm{C}\end{array}$ & $\underbrace{(100)+(110)}_{* *}$ & $(\mathbf{1 0 0})+(110)$ & $\underset{* * * * *}{(100)+(110)}$ & $\underbrace{(100)+(110)}_{* * *}$ & random \\
\hline $\begin{array}{c}\mathrm{Ti} \\
500^{\circ} \mathrm{C}\end{array}$ & $(\mathbf{1 1 1})+(100)$ & (111) $+(100)$ & $\begin{array}{c}(\mathbf{1 1 1})+(100) \\
*\end{array}$ & $\begin{array}{c}(\mathbf{1 1 1})+(100) \\
*\end{array}$ & $(\mathbf{1 1 1})+(100)$ \\
\hline $\begin{array}{c}\mathrm{TiO}_{2} \\
500^{\circ} \mathrm{C}\end{array}$ & $\begin{array}{l}\text { (111) } \\
\text { pyro * }\end{array}$ & (111) & $\begin{array}{c}(\mathbf{1 0 0})+(110) \\
* * * * *\end{array}$ & $\begin{array}{c}(\mathbf{1 0 0})+(110) \\
* * *\end{array}$ & (111) \\
\hline $\begin{array}{c}\mathrm{Ta} \\
500^{\circ} \mathrm{C}\end{array}$ & (111) & (111) & (111) & (111) & (111) \\
\hline
\end{tabular}

Relative quantity of pyrochlore indicated by $(*)$

Temperatures given are for $\mathrm{Ti} / \mathrm{Pt}$ metallization deposition

Table 3: Summary of texture and chemical inertia of the four orientations.

\begin{tabular}{|l|c|c|c|}
\hline metallization & $w$ & $50 \%$ deviation $*$ & possible diffusing species \\
\hline $\mathrm{Ti}-\mathrm{Pt}$ & 2.5 & 1.4 & $\mathrm{Ti}$ \\
\hline $\mathrm{Ta}-\mathrm{Pt}$ & 3 & 1.5 & $\mathrm{Ta}$ \\
\hline $\mathrm{TiO}_{2}-\mathrm{Pt}, 500^{\circ} \mathrm{C}$ & 10.6 & 5.6 & none \\
\hline $\mathrm{TiO}_{2}-\mathrm{Pt}, 650^{\circ} \mathrm{C}$ & 10 & 7.2 & none \\
\hline
\end{tabular}

$w$ : $\quad$ width of theta peak at half height.

*: deviation from normal within which half of the Pt layer falls

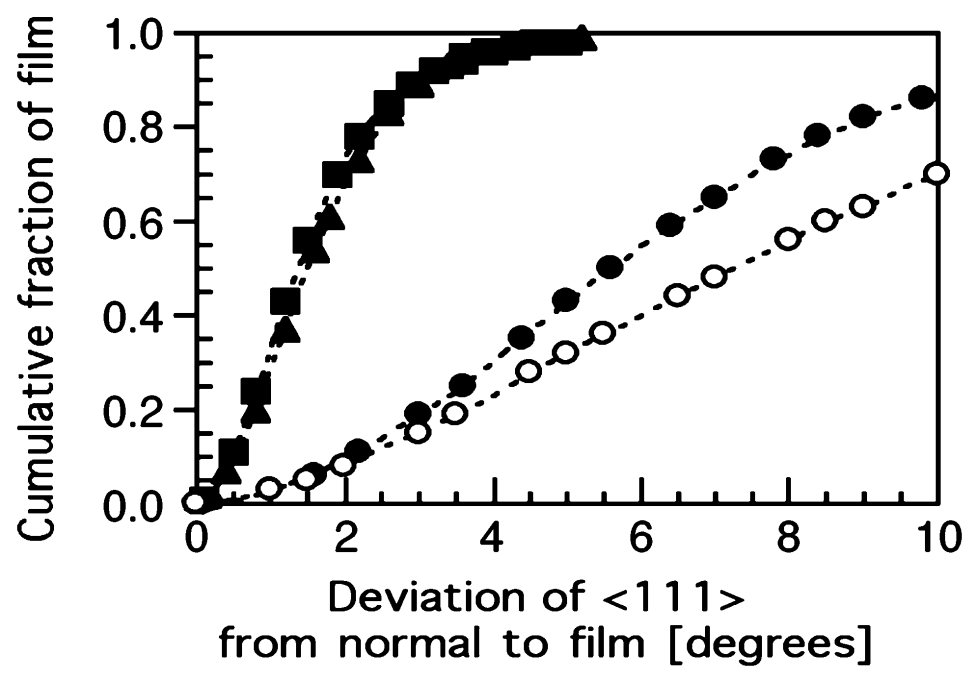

Figure 1. XRD texture analysis of metallizations. 

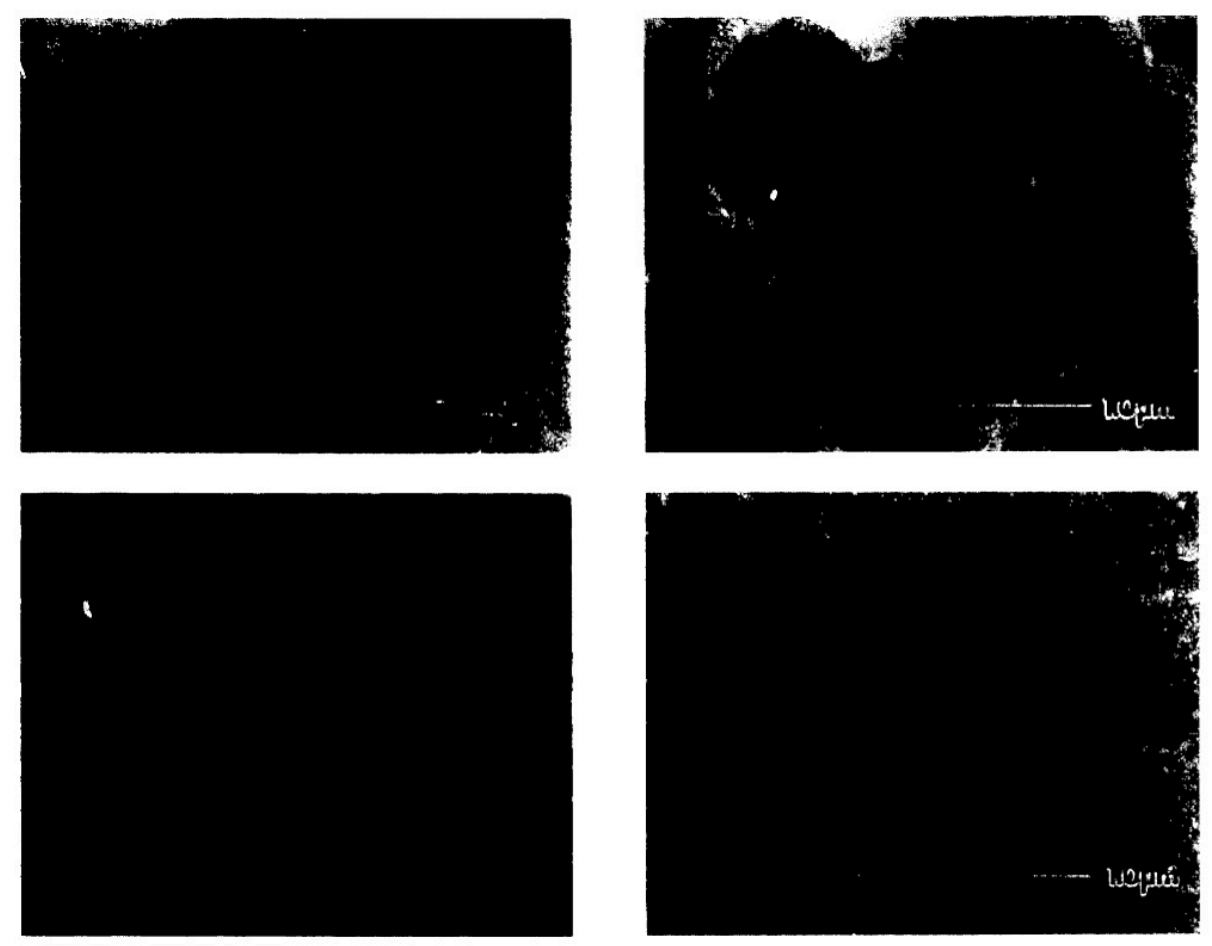

Fig. 2 SEM images of PZT surface for (a) annealing profile \#3 on $\mathrm{TiO}_{2} / \mathrm{Pt}\left(\right.$ deposited at $\left.650^{\circ} \mathrm{C}\right)$, (b) annealing profile \#3 on $\mathrm{Ti} / \mathrm{Pt}\left(500^{\circ} \mathrm{C}\right),(\mathrm{C})$ annealing profile \#5 on $\mathrm{TiO}_{2} / \mathrm{Pt}\left(650^{\circ} \mathrm{C}\right)$, and (d) profile \#5 on $\mathrm{Ti}^{\prime} \mathrm{Pt}\left(500^{\circ} \mathrm{C}\right)$.

\section{Conclusion}

The influence of annealing profile of sol-gel PZT has been investigated for four Pt based metallizations. The (111) orientation observed for the Ti-Pt and Ta-Pt schemes are related to the strong (111) orientation of the Pt and to nucleation sites provided by diffusion and oxidation of the metallic adhesion layers. Conversely, for $\mathrm{TiO}_{2}-\mathrm{Pt}$, nucleation is more difficult, hence the stronger influence of the PZT annealing profile on the microstructure.

\section{Acknowledgements}

The Swiss National Science Foundation is acknowledged for financial support.

\section{References}

[1] Ian M. Reaney, Keith Brooks, Radosveta Klissurska, Czeslaw Pawlaczyk, and Nava Setter, J. Am. Ceram. Soc., 77 (1994) 1209.

[2] Keith G. Brooks, Ian M. Reaney, Radosveta Klissurska, Y. Huang, L. Bursill, and Nava Setter, J. Mater. Res., 9 (1994) 2540.

[3] Radosveta Klissurska, Keith G. Brooks, Ian M. Reaney, Czeslaw Pawlaczyk, Maria Kosec, and Nava Setter, J. Am. Ceram. Soc., 78 (1995) 1513-20.

[4] K.D. Budd, S.K. Dey, and D.A. Payne, Brit. Ceram. Proc., 36 (1985) 107.

[5] K. Sreenivas, Ian Reaney, T. Maeder, and N. Setter, J. Appl. Phys. 75 [1] 232 (1994). 